\title{
An experimental study of an educational intervention to promote maternal self-efficacy in breastfeeding ${ }^{1}$
}

\author{
Regina Cláudia Melo Dodt² \\ Emanuella Silva Joventino ${ }^{3}$ \\ Priscilla Souza Aquino ${ }^{4}$ \\ Paulo César Almeida ${ }^{5}$ \\ Lorena Barbosa Ximenes ${ }^{6}$
}

Objective: to build, validate and assess an educational intervention using the flip chart titled "I Can Breastfeed My Child." Method: an experimental study using a pretest, intervention and posttest, as well as a control group. A total of 201 women, who had been hospitalized immediately, for at least 6 hours, postpartum. The mothers were allocated to the intervention (100 women) or control groups (101 women) according to the length of their hospital stay. The effectiveness of the flip chart was assessed by applying the Breastfeeding Self-Efficacy Scale - Short-Form at admission, discharge and by telephone in the second month postpartum. The intervention and control groups were similar in their socio-demographic, obstetric and gynecological variables. Results: the intervention was beneficial because mothers in the intervention group had higher self-efficacy scores, more mothers continued breastfeeding and mothers had a longer duration of exclusive breastfeeding, both at the time of hospital discharge and at the second month postpartum, with statistically significant associations. Conclusions: this experimental study assessed the educational strategy mediated via the flip chart titled "I Can Breastfeed My Child" as being effective both in increasing self-efficacy and increasing the duration of breastfeeding.

Descriptors: Validation Studies; Educational Technology; Breast Feeding; Self Efficacy; Nursing.

\footnotetext{
1 Paper extracted from doctoral dissertation "Elaboração e validação de tecnologia educativa para autoeficácia da amamentação", presented to Universidade Federal do Ceará, Fortaleza, CE, Brazil. Supported by Conselho Nacional de Desenvolvimento Científico e Tecnológico (CNPq), Brazil, process no 475692/2010-1.

2 PhD, Adjunct Professor, Faculdade Metropolitana da Grande Fortaleza, Fortaleza, CE, Brazil.

${ }^{3} \mathrm{PhD}$, Adjunct Professor, Universidade da Integração Internacional da Lusofonia Afro-Brasileira, Redenção, CE, Brazil.

4 PhD, Adjunct Professor, Universidade Federal do Ceará, Fortaleza, CE, Brazil.

5 PhD, Adjunct Professor, Universidade Estadual do Ceará, Fortaleza, CE, Brazil.

${ }^{6}$ PhD, Associate Professor, Universidade Federal do Ceará, Fortaleza, CE, Brazil.
}

Corresponding Author:

Lorena Barbosa Ximenes

Universidade Federal do Ceará. Departamento de Enfermagem

Rua Alexandre Baraúna, 1115

Bairro: Rodolfo Teófilo

CEP: 60430-160, Fortaleza, CE, Brasil

E-mail: Ibximenes2005@uol.com.br
Copyright $\odot 2015$ Revista Latino-Americana de Enfermagem This is an Open Access article distributed under the terms of the Creative Commons Attribution Non-Commercial License (CC BY-NC).

This license lets others distribute, remix, tweak, and build upon your work non-commercially, and although their new works must also acknowledge you and be non-commercial, they don't have to license their derivative works on the same terms. 


\section{Introduction}

Exclusive breastfeeding is recommended during the first 6 months of life and should be continued as supplementary feeding to at least 2 years of age ${ }^{(1)}$. This recommendation, which is based on several undeniable advantages of breastfeeding ${ }^{(2)}$, aims to prevent approximately 1.3 million infant deaths annually ${ }^{(1)}$.

Nevertheless, less than $40 \%$ of mothers around the world breastfeed their children exclusively for the first 6 months of life ${ }^{(1)}$ and several countries, including Brazil, are still far below the goals advocated by the World Health Organization. In Brazil, according to the latest national research, the median exclusive breastfeeding duration was 60 days, the 25th percentile was 5 days and the 75 th percentile was 150 days $^{(3)}$.

Given that breastfeeding is an effective intervention, that it is feasible to implement on a large-scale and that it has the greatest potential to reduce child mortality in Brazil(4), several strategies have been implemented under the National Policy on Promotion, Protection and Support of Breastfeeding.

We must also consider that in addition to maternal knowledge of the subject, self-efficacy also has a strong influence on the initiation and maintenance of breastfeeding in Brazil( ${ }^{(5-6)}$ and worldwide ${ }^{(7-9)}$. Self-efficacy is the belief in one's personal skill to successfully perform certain tasks or behaviors to achieve desirable outcomes ${ }^{(10)}$ and it is a modifiable factor mainly through health education(11).

Given the importance of self-efficacy, we developed the Breastfeeding Self-Efficacy Scale (BSES)(11), an instrument to assess the self-efficacy of breastfeeding mothers. The short form version of the BSES was designed to be used in a hospital environment to optimize nursing support for the promotion of breastfeeding(7), which has already been validated in Brazil( ${ }^{(6)}$.

Instruments such as the BSES are essential for building educational interventions that are appropriate for the specific characteristics of each population. Thus, this study sought to construct, validate and assess an educational intervention using the flip chart titled "I Can Breastfeed My Child." The hypothesis of this study is that educational intervention using the flip chart titled "I Can Breastfeed My Child" is effective in increasing self-efficacy and also for increasing the duration of breastfeeding.

\section{Method}

This was an experimental study using a design that included a pretest, intervention and posttest, as well as a control group (Figure 1).
The intervention was a flip chart and the process of construction and validation occurred in five stages: 1) the construction and validation of the flip chart were based on literature research and the Breastfeeding SelfEfficacy Scale-Short Form (BSES-SF) ${ }^{(12)}$; 2) the BSESSF was administered to all of the mothers in the study 6 hours postpartum ( $1^{\text {st }}$ contact); 3 ) the intervention group received an explanation from the researcher using the flip chart, while the control group did not receive this explanation; 4 ) the second application of the BSES-SF and an assessment of the infant's diet were performed before hospital discharge ( $2^{\text {nd }}$ contact); and 5 ) the third application of the BSES-SF and an assessment of the infant's diet at two months after childbirth were conducted by telephone ( $3^{\text {rd }}$ contact). The independent variable was the flip chart application. The dependent variable was the maternal self-efficacy and breastfeeding rates.

The study was conducted in a large public maternity hospital that provided tertiary neonatal and perinatal care. This hospital is located in Fortaleza, Ceará, Brazil; it is associated with the National Health System and also trains students from several universities. As a maternity hospital that is certified as baby-friendly and is associated with the Human Milk Bank in Brazil, it sees an average of 600 births per month. The hospital follows the "10 steps to successful breastfeeding" routine, thus babies are offered infant formula only in cases in which breastfeeding is contraindicated-usually due to illness or medication.

The study included mothers who were hospitalized between October 2010 and May 2011, during which there were 2,871 births in the hospital. The inclusion criteria required that the women were in the immediate postpartum period (1-10 days), at least 6 hours after delivery; they were at least 12 years old and authorization and consent was required of the guardian in the case of adolescent mothers; the healthy mothers needed to be able to breastfeed; and the mothers had to have had newborns that weighed more than 2,000 g, given birth after more than 35 weeks of pregnancy and had an APGAR score greater than 6 at 5 minutes after birth. The exclusion criteria excluded women with medical or obstetric complications in the postpartum period; women with medical conditions that made it impossible to breastfeed or contraindicated breastfeeding; mothers whose children were admitted to the intensive care unit; and women with children with some disability or malformation that made breastfeeding impossible. The discontinuation criteria included withdrawal by the 
mother or legal guardian (for adolescents) from the research; a change in phone number during the study, making the continuation of data collection impossible; or the death of the participant or newborn during the study.

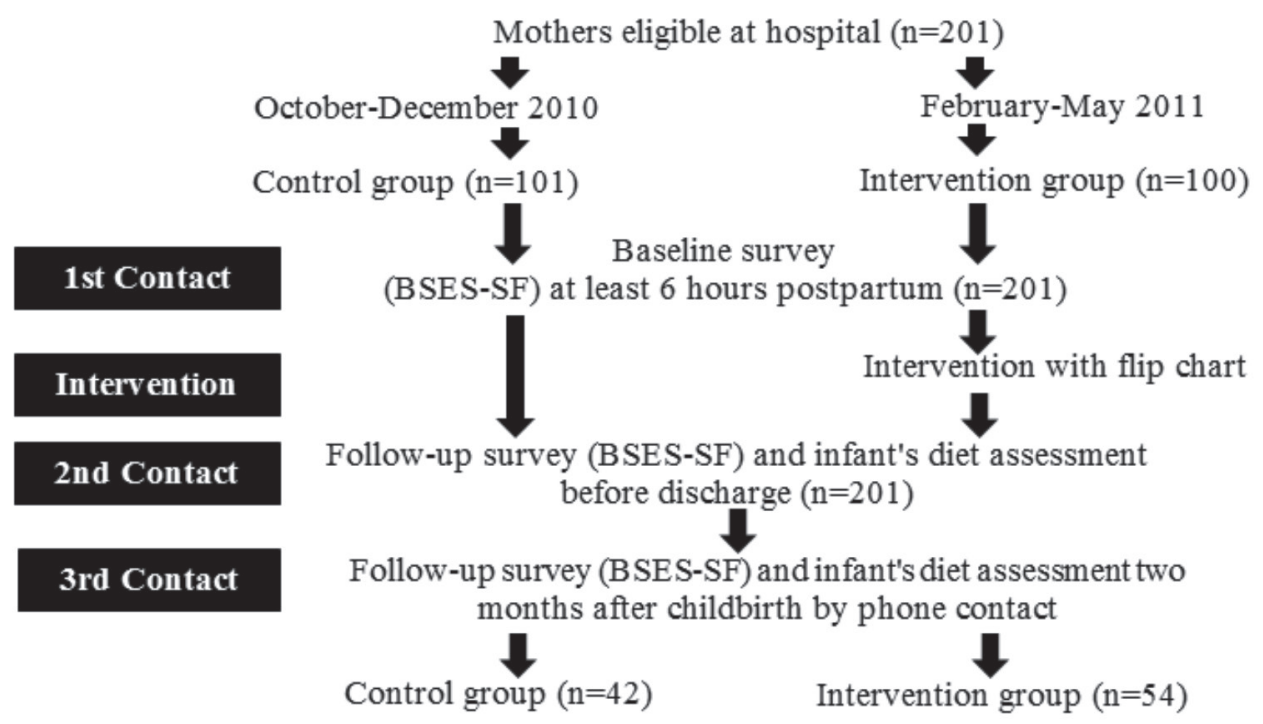

Figure 1 - Flowchart of the study design and the timing of follow-ups with study participants

The sample size was calculated using the formula for intervention studies, setting the significance level at $5 \%$ and the power at $80 \%$, resulting in a sample size of $150^{(13)}$. Considering the possible information loss, we added approximately $30 \%$ to the final sample size and recruited 201 mothers.

To reduce possible bias, we collected data from the intervention and control groups during different periods because if the data was collected during the same period, the mothers could share the information provided in the flip chart, thus compromising the validity of the efficacy intervention.

In the $1^{\text {st }}$ and $2^{\text {nd }}$ contacts (before hospital discharge), the data collection was conducted with the 201 mothers selected according to the inclusion and exclusion criteria: 101 women were in the control group and 100 women were in the intervention group. However, in the $3^{\text {rd }}$ contact, only 96 mothers participated due to difficulties in contacting the participants by phone $42(43.7 \%)$ in the control group and $54(56.2 \%)$ in the intervention group (Figure 1). The researchers compared the phone numbers of the participants with the register at the institution but still failed to maintain communication with some of the participants for the $3^{\text {rd }}$ contact.

The mothers were recruited during the daytime, from Monday to Friday, after being identified as eligible by their medical records. The researchers visited the mothers individually to invite them to participate in the study. After obtaining written consent, they administered the BSES-SF, socio-demographic and clinical-obstetrics questionnaires.

Between the $1^{\text {st }}$ and $2^{\text {nd }}$ contacts, the intervention group received health education through the use of a flip chart that illustrated maternal self-efficacy, while the control group did not receive this intervention.

The flip chart titled "I Can Breastfeed My Child" (40 $\mathrm{cm}$ wide, $32 \mathrm{~cm}$ high) had seven illustrations prepared with the help of a professional service and the Corel Draw X5 Graphics Suite, it contained seven scripts (back of each illustration) that addressed the breastfeeding theme based on the BSES-SF items.

Ten experts validated the appearance and content of the flip chart. These were experts in the area of breastfeeding who had at least two years of experience and they were selected by convenience. The experts judged the six figures and six scripts as clear and understandable, with an agreement level above 50\%. Regarding the degree of relevance of the figures and scripts of the flip chart, two figures presented with $80 \%$ relevance and the others presented with between $90 \%$ and $100 \%$ in the opinion of the experts. For the degree of relevance, we calculated the global Content Validity Index (CVI) and obtained 0.92 for the figures and 0.97 for the scripts, indicating excellent agreement between the experts. The suggestions from the experts were adopted to improve the figures and scripts ${ }^{(12)}$.

Ten lactating mothers participated in a test of the educational strategy presented in the flip chart titled "I 
Can Breastfeed My Child." They were questioned on the type of intervention used as well as its clarity and the mothers' comprehension of the figures shown in the flip chart was also assessed.

After the validation process, the flip chart was used with each mother individually at the patient's bed for an average time of 20 minutes. A single researcher shared the flip chart with the mothers in the intervention group, covering the content in the flip chart using the scripts as well as listening to their questions and clarifying issues to encourage them to begin and to continue breastfeeding. Thus, the researcher initially presented each picture in the flip chart to the mother to hear her opinion on each aspect of breastfeeding. Based on previous experiences, the researcher tried to establish a bond with the patient, giving specific guidance according to the needs of each person. While the mother was looking at each figure in the flip chart, the researcher explained the information using the corresponding script.

Because the flipchart was developed based on the domains of the BSES-SF scale (Technique and Intrapersonal Thoughts), the researcher addressed the technical domain by teaching the adequate positioning of the newborn during feeding, ways to improve comfort during the act of feeding, recognition of the signals of quality lactation and proper suction of the nipple-areolar complex, among other technical issues. While the Interpersonal Thoughts domain worked through the desire to breastfeed, the internal motivation for breastfeeding was based on satisfaction with the breastfeeding experience.

We included three measurement instruments in this study. The BSES-SF, which assesses the maternal selfefficacy in breastfeeding, consists of 14 items organized into two domains (eight items in the technical domain and six items in intrapersonal thoughts) assessed through a five-point Likert scale, from 1 (strongly disagree) to 5 (strongly agree), with scores ranging from 14 to 70 . The total score on the scale was used to calculate a person's self-efficacy. The version of the scale validated for Brazil was shown to be reliable (with a Cronbach's alpha of 0.74 and interclass correlation coefficients ranging from 0.68 to 0.78$)^{(6)}$.

The second questionnaire developed by the researchers addressed the socio-demographic profiles of the participants and collected data related to clinical variables, obstetric history, current pregnancy, childbirth, breast conditions and previous experience with breastfeeding.

The third instrument was used to guide the telephone contact with the participants in both the control and intervention groups and it collected data related to visits to primary care health professionals in the first 15 days after delivery and the guidelines on breastfeeding provided during these visits regarding the infant's diet according to World Health Organization classifications ${ }^{(1)}$.

The participants were interviewed three times, twice during hospitalization: one time at least 6 hours postpartum (baseline study) and the other time close to hospital discharge; and the third time at two months after childbirth (follow-up study). The data collection team included five nursing students trained for the research, and another researcher was responsible only for the presentation of the flip chart. In the training of the student nurses, they had to interview the main researcher repeatedly until the questions were made without influencing the response of the interviewee. The interviews were recorded so that the students could identify aspects of the interviews that could be improved and also so that the professor could provide some explanations.

The data was double-entered into Access 2007 (Microsoft Office) and later exported to SPSS 18.0 for Windows, by which descriptive and inferential analyses were performed. To validate the figures and scripts, we calculated the Content Validity Index (CVI), considering a CVI above 0.90 as being appropriate ${ }^{(14)}$.

The participants were characterized by frequencies (percentages), means, and standard error of the mean (SEM). To compare the intervention and control groups, we applied the Student's t-test and Snedecor's F-test. Along with Snedecor's F-test (ANOVA) significance, we used Tukey's test to determine which pairs were significantly different. To compare the groups at baseline and the groups after two months of intervention, we used the chi-squared test and either Student's t-test or the Mann-Whitney test, considering a critical alpha of 0.05 .

In the analyses of the type of feeding, exclusive breastfeeding was defined as when the child received only breast milk and no other liquids or solids except for drops or syrups containing vitamins, oral rehydration salts, mineral supplements or medicines. Breastfeeding is a concept understood as a child receiving breast milk, regardless of whether the child had received other foods ${ }^{(1)}$.

The Research Ethics Committee of the Assis Chateaubriand Maternity School approved the study. All of the study participants in the intervention and control groups as well as the experts who assessed the flip chart and the mothers in the intervention test were informed of their rights, assured of data confidentiality and were given the opportunity to withdraw from the study at any time. 


\section{Results}

The total study sample $(n=201)$ was divided into two groups: control $(n=101)$ and intervention $(n=100)$. There was no difference between the intervention and control groups with regard to age $(p=0.116)$, per capita income $(0.120)$, receiving help for household chores $(p=0.178)$, and the existence of a place designated for breastfeeding at home $(p=0.273)$. There was no difference between the groups with regard to the average years of schooling $(0.774)$, with 9.38 years in the intervention group and 9.49 years in the control group. Furthermore, with regard to the obstetric variables, we observed homogeneity between the groups regarding the number of pregnancies $(p=0.138)$, number of abortions $(p=0.083)$ and period of breastfeeding $(p=0.546)$. Thus, the groups were similar, ensuring that the differences found between them were actually due to the intervention and not to selection biases.

The BSES-SF scores ranged from 14 to 70 , the minimum and maximum scores, respectively; higher scores indicated greater maternal self-efficacy. However, to assess the variable maternal self-efficacy in breastfeeding, we adjusted the total scores obtained from the BSES-SF so that the minimum value was zero and the maximum value was 100 (Table 1, Figure 2).
The mean score of the BSES-SF at baseline in the intervention group was $74.1(\mathrm{SEM} \pm 1.2)$ and the control group $72.8(\mathrm{SEM} \pm 1.0)$ (ANOVA, $\mathrm{p}=0.384)$. The scores at the $2^{\text {nd }}$ contact, after the flip chart was used with the intervention group and after the conventional guidelines of the institution were used with the control group, were $77.5(\mathrm{SEM} \pm 1.0)$ and $75.1(\mathrm{SEM} \pm 1.0)$ (ANOVA $p=0.113)$, respectively, verifying that between the $1^{\text {st }}$ and $2^{\text {nd }}$ contacts, the mean scores were very close, with an increase of 3.4 points in the intervention group and an increase of 2.3 points in the control group. The BSESSF scores were higher in the intervention group (79.1, $\mathrm{SEM} \pm 1.2)$ than in the control group (70.7, $\mathrm{SEM} \pm 2.5)$ two months after childbirth (the $3^{\text {rd }}$ contact), verifying that the intervention group scores increased by 5 points, while the control group score decreased by 2.1 points (Table 1).

At the $1^{\text {st }}$ contact, $100 \%$ of the mothers in both groups continued breastfeeding, with no differences between the two groups. However, when the $1^{\text {st }}$ contact was compared with the $3^{\text {rd }}$ contact, all of the participants $(100 \%)$ in the intervention group continued exclusively breastfeeding, while only $41 \%$ of the participants in the control group still offered breast milk to their children (Table 1 ).

Table 1 - Comparison of the Main Outcomes between the $1^{\text {st }}$ and $3^{\text {rd }}$ Contacts According to Group. Fortaleza, CE, Brazil, 2010-2011

\begin{tabular}{|c|c|c|c|c|c|c|}
\hline & \multicolumn{2}{|c|}{ Intervention Group } & \multirow[b]{2}{*}{$\rho$} & \multicolumn{2}{|c|}{ Control Group } & \multirow[b]{2}{*}{$\rho$} \\
\hline & $\begin{array}{l}1^{\text {st }} \text { Contact* } \\
\text { Mean } \pm \mathrm{SD}^{\ddagger}\end{array}$ & $\begin{array}{l}3^{\text {rd }} \text { Contact }^{\dagger} \\
\text { Mean } \pm \mathrm{SD}^{\ddagger}\end{array}$ & & $\begin{array}{l}1^{\text {st }} \text { Contact } \\
\text { Mean } \pm \mathrm{SD}^{\ddagger}\end{array}$ & $\begin{array}{l}3^{\text {rd }} \text { Contact }^{\dagger} \\
\text { Mean } \pm \mathrm{SD}^{\ddagger}\end{array}$ & \\
\hline Scale scores & $55.5 \pm 6.63$ & $58.2 \pm 5.02$ & 0.032 & $54.7 \pm 5.68$ & $53.5 \pm 9.15$ & 0.332 \\
\hline \multirow[t]{2}{*}{ Change } & $2.54 \pm 8.28$ & & & $-1.69 \pm 11.16$ & & \\
\hline & No. (\%) & No. (\%) & & No. $(\%)$ & No. (\%) & \\
\hline $\begin{array}{l}\text { Exclusive } \\
\text { breastfeeding } \$\end{array}$ & $100(100 \%)$ & $54(100 \%)$ & & $101(100 \%)$ & $35(41.0 \%)$ & \\
\hline
\end{tabular}

* IG $\times$ CG in $1^{\text {st }}$ contact: $p=0.397 ;+$ IG $\times$ CG in $3^{\text {rd }}$ contact: $p=0.002 ;$ ₹D = Standard deviation; $\S$ Z-test applied for proportions of independent data $p<0.001$

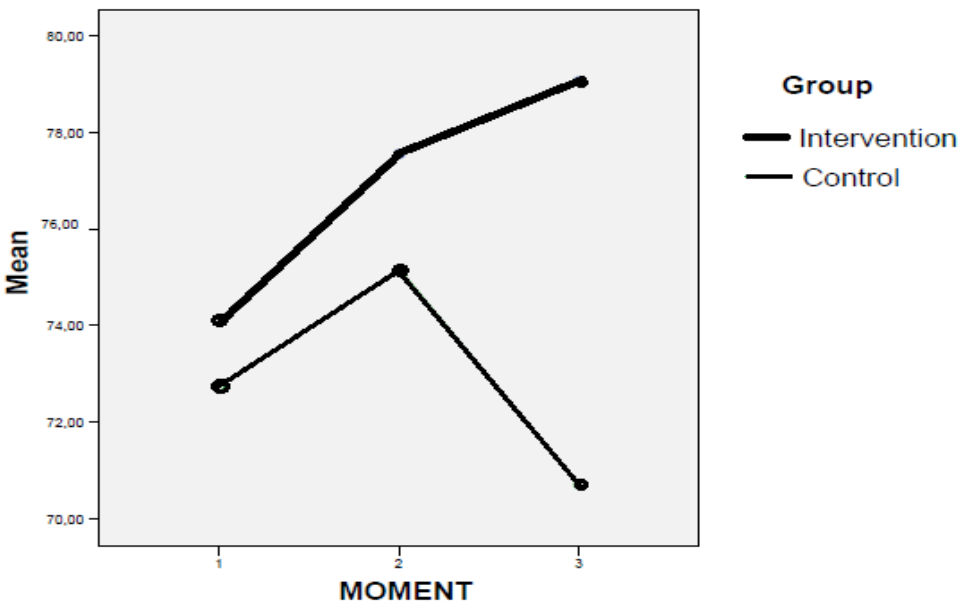

Figure 2 - Evolution of mean self-efficacy in breastfeeding in both groups. Fortaleza, CE, Brazil, 2010-2011 
With regard to the influence of self-efficacy on continued breastfeeding, we inferred that in the intervention group, the mean scores of the BSES-SF on exclusive breastfeeding were higher than the mean scores on non-exclusive breastfeeding $(p=0.003)$. In the control group, the mean duration of exclusive breastfeeding and non-exclusive breastfeeding were similar $(p=0.267)$. The duration of exclusive breastfeeding in the intervention group (64.31) was considerably higher than the average duration of exclusive breastfeeding in the control group (56.96) $(p<0.05) \quad($ Table 2$)$. Thus, the strategy of health education fostered by the flip chart titled "I Can Breastfeed My Child" was effective in increasing selfefficacy and the duration of breastfeeding.

Table 2 - Comparison of Food Types and the Mean of the BSES-SF Scores at the 3rd Contact According to Group. Fortaleza, CE, Brazil, 2010-2011

\begin{tabular}{|c|c|c|c|c|c|}
\hline Group & & & Mean & SEM* & $\rho$ \\
\hline \multirow[t]{2}{*}{ Intervention } & Total in $3^{\text {rd }}$ contact & $\begin{array}{c}\text { Exclusive } \\
\text { breastfeeding }\end{array}$ & 64.31 & 0.950 & 0.003 \\
\hline & & Breastfeeding & 58.33 & 1.563 & \\
\hline \multirow[t]{2}{*}{ Control } & Total in $3^{\text {rd }}$ contact & $\begin{array}{c}\text { Exclusive } \\
\text { breastfeeding }\end{array}$ & 56.96 & 1.194 & 0.267 \\
\hline & & Breastfeeding & 54.58 & 1.807 & \\
\hline
\end{tabular}

*SEM $=$ Standard error of the mean.

\section{Discussion}

The variation in the BSES-SF scores was more evident in the intervention group than in the control group. Between the $1^{\text {st }}$ and $2^{\text {nd }}$ contacts, the scores increase by 3.4 points in the intervention group and 2.3 points in the control group. However, between the $2^{\text {nd }}$ and $3^{\text {rd }}$ contacts, the scores in the intervention group increased by 1.6 points but decreased by 4.4 points in the control group. Other studies have also shown an improvement in maternal self-efficacy scores among those who received interventions by specialists $^{(15-16)}$, increasing by up to 15.1 points on the BSES-SF( ${ }^{(8)}$. In Australia, an intervention based on Bandura's self-efficacy theory increased breast-feeding self-efficacy. Furthermore, at 4 weeks postpartum, women in the intervention group showed a trend toward breast-feeding their infants for longer, and more exclusively than those in the control group ${ }^{(15)}$. In Canada, after a self-efficacy intervention, the mothers in the intervention group had higher mean BSES-SF scores at 4 and 8 weeks postpartum than the control group.

Educational practices are considered effective when they influence the beliefs that people have in their own abilities. Education also affects how people will behave when facing adversity and also influences the duration of adversity and the amount of effort people will exert to confront adversity ${ }^{(17)}$. Maternal self-efficacy may also have been influenced by personal experiences, verbal persuasion at the time of the educational intervention and vicarious experiences, such as observing other women breastfeeding at the maternity hospital where the study was conducted(18).

For both the control and intervention groups, the scores increased for the items in the interpersonal domain between the $1^{\text {st }}$ and $2^{\text {nd }}$ contacts, while scores for items in the technical domain decreased between the $2^{\text {nd }}$ and $3^{\text {rd }}$ contacts. The practice and technique of breastfeeding are factors that cause insecurity in mothers, even in the group that received the intervention and when the impact of the intervention was not sufficient after the mothers of having returned home. The interventions must occur beyond the maternity context, with an effective daily support network that teaches, supports and demonstrates the ideal practices related to breastfeeding so that mothers may prevent early weaning.

Our literature review identified that the main factors that influence breastfeeding among Hispanics are acculturation, interpersonal support, self-efficacy and immediate competing demands(19). Thus, information and guidance should be extended to the family support network because many of the women lose confidence in themselves after returning home from the hospital due to the pressure from family and friends to provide infant formulas to their children ${ }^{(20)}$.

A study conducted in Chile showed some factors that negatively influence the maintenance of exclusive breastfeeding, such as maternal age up to 25 years, so the need for educational and social strategies in this group is shown ${ }^{(21)}$. 
In addition to raising the scores of maternal selfefficacy, educational intervention presented through the flip chart titled "I Can Breastfeed My Child" prolonged the duration of breastfeeding and $100 \%$ of the mothers in the intervention group continued breastfeeding in the follow-up study compared to only $41 \%$ of the mothers in the control group. A similar result was found in Japan, where, at the one-month follow-up, breastfeeding declined by approximately $24 \%$ in the control group but only by $10 \%$ in the intervention group ${ }^{(8)}$.

In the intervention group, the mean scores on the BSES-SF with regard to exclusive breastfeeding were higher than the mean scores on non-exclusive breastfeeding and the average BSES-SF scores with regard to exclusive breastfeeding in the intervention group was significantly higher than those scores in the control group. This result corroborated with an Australian study in which self-efficacy in breastfeeding was higher among mothers who maintained exclusive breastfeeding compared with those who breastfed partially and those who had weaned their children. Guidance on breastfeeding, support regarding the duration of breastfeeding and maternal confidence are associated with breastfeeding at 1 month postpartum(22).

A study using various strategies (individual consultation, preparation courses for parenting/ childbirth, and domicile visits) without the focus on selfefficacy showed that the nursing intervention was not a determinant for the prevalence of breastfeeding(23).

We emphasize that self-efficacy should be considered in interventions related to breastfeeding, and we should identify the level of these mothers' self-efficacy before developing any strategies ${ }^{(7)}$ for implementation during the prenatal through the postpartum periods ${ }^{(24)}$. This variable is a strong predictor of breastfeeding duration because the risk ratio for weaning increases by approximately $18 \%$ among women who have lower selfefficacy scores on the BSES ${ }^{(25)}$.

\section{Conclusion}

Despite the numerous benefits of breastfeeding, it is still a practice that requires intervention to ensure continuity. This study found that educational intervention enhanced by the flip chart titled "I Can Breastfeed My Child" provided positive results regarding increased maternal self-efficacy that was related to a greater adherence to, and a longer duration of breastfeeding at two months postpartum. Therefore, it is important that nurses use health education strategies such as this flip chart to promote breastfeeding. It is necessary to engage in further research in other populations and in other contexts, especially during other stages of pregnancy and childbirth, for example, during the prenatal and remote postpartum periods, so that we can assess the influences of this intervention over longer periods of time.

The limitation of this study was the difficulty in reestablishing phone contact with the study participants during the final stage of data collection, which made it impossible to follow up with some mothers in the study.

\section{References}

1. World Health Organization. Indicators for assessing infant and young child feeding practices: conclusions of a consensus meeting held 6-8 November 2007 in Washington D.C. Geneva: World Health Organization; 2008.

2. Rea MF. Benefits of breastfeeding and women's health. Jornal de Pediatria. 2004;80(Supll 5):142-6.

3. Warkentin S, Taddei JAAC, Viana KJ, Colugnati FAB. Exclusive breastfeeding duration and determinants among Brazilian children under two years of age. Rev Nutr. 2013;26(3):259-69.

4. Darmstadt GL, Bhutta ZA, Cousens S, Adam T, Walker N, Bernis L. Evidence-based, cost-effective interventions: how many newborn babies can we save? Lancet. 2005;365(9463):977-88.

5. Oriá MOB, Ximenes LB, Almeida PC, Glick DF, Dennis $\mathrm{CL}$. Psychometric assessment of the Brazilian version of the Breastfeeding Self-Efficacy Scale. Public Health Nurs. $2009 ; 26(6): 574-83$

6. Dodt RCM, Ximenes LB, Almeida PC, Oria MOB, Dennis $\mathrm{CL}$. Psychometric assessment of the short form version of the Breastfeeding Self-Efficacy Scale in a Brazilian sample. J Nurs Educ Practice. 2012;2(3):66-73.

7. Dennis CL. The breastfeeding self-efficacy scale: Psychometric assessment of the short form. J Obstet Gynecol Neonat Nurs. 2003;32(6):734-44.

8. Awano M, Shimada K. Development and evaluation of a self-care program on breastfeeding in Japan: A quasi-experimental study. Int Breastfeed J. 2010;5(9):1-10.

9. Imdad A, Yakoob MY, Bhutta ZA. Effect of breastfeeding promotion interventions on breastfeeding rates, with special focus on developing countries. BMC Public Health. 2011;11(Supll 3):24-32.

10. Bandura A. Self-efficacy: Toward a unifying theory of behavioral change. Psychol Rev. 1977;84(2):191-215. 
11. Dennis CL, Faux S. Development, and psychometric testing of the Breastfeeding Self-Efficacy Scale. Res Nurs Health. 1999;22(5):399-409.

12. Dodt RCM, Ximenes LB, Oria MOB. Validation of a flip chart for promoting breastfeeding. Acta Paul Enferm. 2012;25(2):225-30.

13. Kirby A, Gebski V, Keech AC. Determining the sample size in a clinical trial. Med J Aust. 2002;177(5):256-7.

14. Alexandre NMC, Marina ZOC. Validade de conteúdo nos processos de construção e adaptação de instrumentos de medidas. Ciênc Saúde Coletiva. 2011;16(7):3061-8. 15. Nichols J, Schutte NS, Brown RF, Dennis CL, Price I. The impact of a self-efficacy intervention on shortterm breast-feeding outcomes. Health Educ Behav. 2009;36(2):250-9.

16. McQueen KA, Dennis CL, Stremler R, Norman CD. A pilot randomized controlled trial of a breastfeeding selfefficacy intervention with primiparous mothers. J Obstet Gynecol Neonat Nurs. 2011;40(1):35-46.

17. Smith BJ, Tang KC, Nutbeam D. WHO health promotion glossary: New terms. Health Promotion Int. 2006;21(4):340-5.

18. Narchi NZ, Fernandes RAQ, Dias LA, Novais DH. Variables that influence the maintenance of exclusive breastfeeding. Rev Esc Enferm USP. 2009;43(1):87-94. 19. Schlickau JM, Wilson ME. Breastfeeding as a healthpromoting behavior for Hispanic women: literature review. J Adv Nurs. 2005;52(2):200-10.

20. Bueno LGS, Teruya KM. The practice of breastfeeding counseling. J Pediatria. 2004;80(supl 5):126-30.

21. Pino VJL, López EMA, Medel IAP, Ortega SA. Factores que inciden en la duración de la lactancia materna exclusiva en una comunidad rural de Chile. Rev. chil. nutr. 2013;40(1):48-54.

22. Blyth R, Creedy DK, Dennis CL, Moyle W, Pratt J, Vries MD. Effect of maternal confidence on breastfeeding duration: An application of breastfeeding self-efficacy theory. Birth. 2002;29(4):278-84.

23. Graça LCC, Figueiredo MCB, Conceição MTCC. Contributions of the nursing intervention in primary healthcare for the promotion of breastfeeding. Rev. Latino-Am. Enfermagem. 2011;19(2):429-36.

24. Semenic S, Loiselle C, Gottlieb L. Predictors of the duration of exclusive breastfeeding among first-time mothers. Res Nurs Health. 2008;31(5):428-41.

25. Baghurst $P$, Pincombe J, Peat B, Henderson A, Redding E, Antoniou G. Breastfeeding self-efficacy, and other determinants of the duration of breastfeeding in a cohort of first time mothers in Adelaide, Australia. 